Revista Voluntas: estudos sobre Schopenhauer - $1^{\circ}$ semestre 2011 - Vol. 2 - No 1 - ISSN: 2179-3786 - pp. 48-62

\title{
A crítica de Schopenhauer à concepção de um uso prático da razão pura
}

\author{
Glauber Cesar Klein \\ Mestrando em Filosofia pela UFPR
}

\begin{abstract}
RESUMO: O artigo tem como proposta analisar um primeiro momento da crítica de Schopenhauer à teoria moral de Kant. Este primeiro momento é a crítica à concepção de um uso puro prático da faculdade racional; ele tem três passos, a saber, crítica à (i) idéia de uma mesma razão que seria responsável pelo fundamento teórico $e$ prático, à (ii) falta de fundação ou dedução deste suposto uso prático da razão pura e/ou acusação de insuficiência da única tentativa realizada por Kant neste sentido e (iii) acusação de um pressuposto transcendente imbricado nesta concepção, a saber, que um uso prático da razão pura, isto é, uma determinação racional a priori da vontade, teria como fundamento oculto a psicologia racional. Antes destes três passos, no entanto, analisaremos qual a necessidade, para Schopenhauer, dessa crítica à moral kantiana, buscando assim indicar que a polêmica visava também, e talvez sobretudo, os póskantianos.
\end{abstract}

PALAVRAS-CHAVE: Razão prática, Dever, Genealogia da moral.

ABSTRACT: The purpose of this paper is to analyze an initial moment of Schopenhauer's critique to Kant's moral theory, that is, the critique of the concept of a pure practical use of rational faculty. It has three steps, namely, critique to (i) an idea of the same reason that would account for the theoretical and practical foundation, to (ii) lack of foundation or deduction of this alleged practical use of pure reason and/or prosecution of insufficiency of the only attempt made by Kant in this regard and (iii) charge a transcendent overlapping assumption in this view, namely that a practical use of pure reason, that is, a priori a rational determination of the will, would have as a hidden ground the rational psychology. Before these three steps, however, we will analyze wich is the necessity, for Schopenhauer, of this critique of Kantian morality, thus seeking to indicate that the controversy sought also, perhaps primarily, the poskantians.

KEYWORDS: Practical reason, Duty, Genealogy of moral.

\section{Introdução}

Concebendo o princípio essencial de todas as coisas como um mero ímpeto cego, Arthur Schopenhauer estabelece uma investigação sem precedentes ao longo da história da filosofia. Esta investigação inovadora, contudo, tem como preocupação fundamental não ultrapassar os limites impostos pela Crítica. Admirador declarado da Estética Transcendental, Schopenhauer adota - e louva como verdade mais profunda e sólida de toda a filosofia ${ }^{1}$ - a distinção entre fenômeno e coisa-em-si. Tudo que podemos conhecer

\footnotetext{
${ }^{1}$ Crítica da filosofia kantiana (doravante, CK), p. 526.
} 
positivamente encontra-se no âmbito fenomênico. A coisa-em-si, por sua vez, mantém-se incógnita indecifrável pela razão.

Não obstante este drama instaurado pelo reconhecimento da impotência da razão em conhecer positivamente objetos transcendentes, a metafísica continua possível, necessária e praticável. Não pode mais ser entendida como estrada de ouro que nos leva à glória do conhecimento absoluto, brilhante e translúcido cristal; mas ainda assim se mantém como única via de significação, pavimentada com pedras mais humildes e destino menos magnífico, decerto, mas por isso mesmo mais confiável, com menos curvas acidentais e escarpadas. É o que nos diz Schopenhauer.

Deste modo, esta metafísica imanente não chegará à essência do mundo por um sutil e sofisticado raciocínio puro, todo ele sustentado por conceitos abstratos, pois estes não podem de forma alguma extrapolar a experiência sensível sem perder suas significações ${ }^{2}$. Ela precisa, ao contrário, perseguir o amplo domínio do sentimento, que engloba tudo que não é conceito abstrato. A fim de diminuir esta imensa esfera, o filósofo toma o cuidado de distinguir o sentimento (Gefühl) da sensação (Empfindung). Esta, como subespécie, deve ser reservada às afecções corpóreas, aquele, agora não entendido e confundido com a mera afecção, deve ser identificado como modificação da consciência ${ }^{3}$. Voltando-se ao simples sentimento entendido como modificação da consciência ${ }^{4}$, a metafísica pode trazer à luz o mais íntimo de tudo: o Querer. Nada é mais imediato a nós que o Querer. Ele, prescindido da gerência racional, é a única solução para aquele enigma que a razão falhara em encontrar por mais de dois mil anos!

Externo à razão, este Querer não conhece tempo, espaço, finalidade ou razão de ser. Estes conceitos ou condições de toda experiência, em verdade, nada mais são que manifestações e meios do Querer. Mas, essência de toda existência, o que quer o Querer? Sem objetos, télos ou razão, só pode querer a si mesmo, isto é, querer a existência. Este querer, pois, é Vontade de viver 5 .

\footnotetext{
${ }^{2}$ Sobre a teoria (dos limites) da linguagem e da razão, ver Barboza, J., Os limites da expressão, linguagem e realidade em Schopenhauer, 2005.

${ }^{3}$ O mundo como vontade e como representação (doravante, MVR I), p. 101.

${ }^{4}$ Via de acesso à coisa-em-si já prenunciada por Fichte, por ocasião de seu diálogo com os primeiros objetores da concepção kantiana de coisa-em-si, cf. o prefácio da primeira edição de Sobre o conceito da Doutrina-da-ciência, p. 5, nota 1. Sobre isto, ver também: Bonaccini, J. A., Kant e o problema da coisa em si no idealismo alemão, p. 109.

${ }^{5} \mathrm{O}$ termo "vontade", como (als) coisa-em-si, não é uma escolha - como o seria se a coisa-em-si tivesse um conteúdo dedutível -, mas sim necessário por uma denominatio a fortiori. A vontade humana é o fenômeno
} 
Como vimos, esta Vontade de viver prescinde de toda racionalidade, e é por isso mesmo que pode ser pensada como (als) coisa-em-si. Não está submetida a nenhuma condição formal, mas precisa ser pensada exatamente como oposição aos limites da razão, ou melhor, ao princípio de razão suficiente ${ }^{6}$, condição de conhecimento do ponto de vista (Standpunkt) da representação. Contrariamente a todo objeto racional, a Vontade é livre, sem-fundamento (Grundlos), atemporal e indivisível. - A que leis obedecerá este mero ímpeto cego (blosser blinder Drang)?

De fato, é uma contradição flagrante denominar a Vontade livre, e no entanto prescrever-lhe leis segundo as quais deve querer: 'dever-querer!', ferro-madeira! (- »wollen soll« - hölzernes Eisen!) À luz de toda a nossa visão, contudo, a Vontade é não apenas livre mas até mesmo todo-poderosa. Dela provém não só seu agir, mas também seu mundo. Tal qual ela é, assim aparecerá seu agir, assim aparecerá seu mundo: ambos são seu autoconhecimento e nada mais. Ela determina a si e justamente por aí determina seu agir e seu mundo: estes dois são ela mesma, pois exterior à Vontade não há nada. Só assim ela é verdadeiramente autônoma; sob qualquer outro aspecto, entretanto, é heterônoma. Nossa tarefa filosófica, portanto, só pode ir até a interpretação e a explanação ( $z u$ deuten und zu erklären) do agir humano e suas diversas e até mesmo opostas máximas, das quais ela é expressão viva, de acordo com sua essência mais íntima e conteúdo ${ }^{7}$.

Pensar qualquer lei pura racional como princípio determinante do querer, portanto, seria ignorar a autonomia da essência tempestuosa e cega do mundo. A efetividade de princípios a priori na determinação da Vontade seria comparável, para usarmos uma metáfora schopenhaueriana, a "um tiro contra um rochedo" ${ }^{8}$. E a razão pura prática, tal como é pensada por Kant - isto é, como faculdade que produz a priori deveres absolutos

mais claro, próximo e perfeito da essência de todas as coisas; é por isso, pois, que o termo "vontade" é necessariamente o adequado para designar a coisa-em-si. Cf. MVR I, pp. 169ss.

${ }^{6}$ Permanece ruidosa essa tradução: princípio de razão suficiente. O termo Grund, do original - Satz vom zureichenden Grunde -, pode ser traduzido ou por fundamento ou por razão (todavia, no sentido de fundamento). Contudo, parece essencial salientar o termo Grund como fundamento, pois o seu oposto será uma caracterização nuclear da Vontade: Grundlos. A Vontade é sem fundamento, e não apenas sem razão isto é, a oposição não é apenas a motivos racionais, mas a qualquer forma de condicionamento por formas presentes na representação. Há ainda variantes ao termo Grund que também serão explorados no decorrer do léxico schopenhaueriano que não são bem traduzidos apenas por oposição à razão, mas sim a fundamento, como Unergründliche, Hintergrunde, Abgrund. J. M. A. Barrenechea, em El discurso de Schopenhauer sobre la «cosa en si», empregou a tradução princípio de fundamento suficiente. A despeito dessas razões, permanece a fluência consagrada à formulação latina, marcando a reação à ratio iluminista por parte de Schopenhauer.

${ }^{7}$ MVR I, pp. 354-5.

${ }^{8}$ MVR I, p. 455. 
que determinam a vontade -, inoperante e ingênua. Seguir a argumentação schopenhaueriana, concedendo à identificação da Vontade com a coisa-em-si, leva sem dúvida à falência do livre-arbítrio, do formalismo, da postulação de imortalidade da alma, de um Soberano Bem, etc. Enfim, aceita a metafísica de Schopenhauer, a ética kantiana torna-se uma complexa bolha de sabão, brilhante e inútil.

Entretanto, Schopenhauer também se serviu, em sua campanha antiformalista, de argumentação independente de suas audaciosas soluções metafísicas. Sobre o fundamento da moral é uma obra notável, justamente, por fundar a sua moral sem se utilizar de sua metafísica: procura o fundamento analiticamente, com a guarda de uma refutação sistemática da moral kantiana. E tal como na fundamentação da moral, também nesta crítica o filósofo não se utiliza de sua metafísica estabelecida. Tenta solapar a ética kantiana de modo totalmente analítico. Assim, independente de sua metafísica da Vontade, encontramos em Schopenhauer um ataque frontal à moral kantiana. Também em sua obra Crítica à filosofia kantiana, publicada como apêndice a $O$ Mundo como vontade e como representação, nosso filósofo ataca a ética kantiana sem se valer dos ganhos de sua inversão da primazia da razão sobre a Vontade.

Isto posto, este artigo tem como proposta analisar, justamente, o primeiro momento desta crítica que se propõe puramente analítica. Este primeiro momento é a crítica à concepção de um uso puro prático da faculdade racional. Ela tem três passos, a saber, crítica à (i) idéia de uma mesma razão que seria responsável pelo fundamento teórico $e$ prático, à (ii) falta de fundação ou dedução deste suposto uso prático da razão pura e/ou acusação de insuficiência da única tentativa realizada por Kant neste sentido e (iii) acusação de um pressuposto transcendente imbricado nesta concepção, a saber, que um uso prático da razão pura, isto é, uma determinação racional a priori da vontade, teria como fundamento oculto a psicologia racional. Antes destes três passos, no entanto, analisaremos qual a necessidade, para Schopenhauer, dessa crítica à moral kantiana.

\section{Crítica à concepção de Razão Prática Pura}

\subsection{Da necessidade de uma refutação da moral kantiana}


É na obra Sobre o fundamento da moral que encontramos de maneira extensa e detalhada a crítica à moral kantiana. Ela precede - sendo quase metade da obra - a investigação positiva do fundamento dado por Schopenhauer à ética. Assim, a crítica à moral kantiana representa para o filósofo uma etapa necessária de sua investigação. Pode-se ter certeza que o alvo da crítica de Schopenhauer engloba toda ética fundada em pressupostos teológicos ou de outra natureza transcendente. Mas a que se deve então a preocupação demorada especialmente na ética de Kant, que se distingue justamente pelo caráter crítico?

O filósofo apresenta duas justificativas. A primeira considera que Kant estabeleceu uma revolução ${ }^{9}$ também na ética, alcançando reais vantagens sobre as anteriores, o que inclui uma fundação supostamente não-dogmática. Assim, a moral kantiana era lida à época como estando à frente de todas as demais, e os pós-kantianos seguiam-na inapelavelmente, arriscando apenas, segundo Schopenhauer, "mudanças na exposição e na expressão" 10 . Ao atacar o fundamento moral kantiano Schopenhauer visava, pois, refutar não apenas Kant, mas toda a filosofia moral feita à época, sobretudo na Alemanha. A estratégia de Schopenhauer foi derrubar o gigante, e assim levar ao chão também os pigmeus que palravam em seus ombros.

A segunda justificativa apresenta a moral kantiana como diametralmente oposta à sua, que será fundada páginas depois. Esta longa e demorada análise atende, portanto, a uma segunda estratégia: confrontar os opostos (Änderungen in der Darstellung und den Ausdrücken anders aufgeputzt ${ }^{11}$. Assim nos diz o filósofo:

Mas, em especial, já que os contrários se esclarecem (die Gegensätze sich erläutern), a crítica da fundamentação da moral kantiana é a melhor preparação e orientação (die beste Vorbereitung und Anleitung) e mesmo o caminho direto para a minha, como sendo aquela que, nos pontos

\footnotetext{
${ }^{9}$ Sobre o Fundamento da Moral (doravante, M/M), p. 15. O termo usado é "reforma moral", "Moralreform" (cf, Über die Grundlage der Moral. Kleinere Schriften. Sämtliche Werke, Band III: Bearbeitet und Heraugegebt von Wolfgang Frhr. Von Löhnheysen. Frankfurt am Main: Suhrkamp, 1998, p. 114 (doravante, citado junto à tradução brasileira, entre parêntes).

${ }^{10}$ M/M. p. 15 (115).

${ }^{11}$ Cf. Cartwright, D.E., Schopenhauer's Narrower Sense of Morality, p. 263: "In place of Kant's non-empirical, rationalistic, and prescriptive ethics, Schopenhauer develops an empirical, voluntaristic, descriptive virtue ethics...". Também considerar, do mesmo ensaio, p. 254: "Nowhere else and never again would Schopenhauer express such an extreme opposition to the views of his philosophical ancestor".
} 
essenciais, opõe-se diametralmente à de Kant (als welche in den wesentlichsten Punkten der Kantischen diametral entgegengesetzt ist) ${ }^{12}$.

Fundar a sua moral, que será apresentada como altamente original, sem apresentar os erros da teoria oposta, seria completar apenas parte da tarefa, e a parte positiva "seria compreendida apenas pela metade" 13 .

Esta segunda justificativa dá razão à nossa escolha apresentada na primeira parte do texto, qual seja, de não partir da Metafísica da Vontade para então apenas concluir a inoperância de prescrições que intentam determinar o mero ímpeto cego, essência deste mundo, mas sim considerar, à parte, a tentativa de refutação analítica do fundamento da moral kantiana. Resta, todavia, uma alternativa: talvez seja necessário considerar alguns passos da teoria positiva de Schopenhauer, mas não necessariamente sua concepção de uma Vontade pré-racional e indeterminável. É isto que agora veremos.

\subsection{Inadmissão da razão pura prática}

Schopenhauer aponta que Kant não definiu precisamente o que é razão, nem na Crítica da Razão Pura nem na Crítica da Razão Prática. Na primeira Crítica, Kant apresenta ao todo, segundo Schopenhauer ${ }^{14}$, sete definições: 1. Faculdade dos princípios $a$ priori $^{15}$; 2. Faculdade dos princípios, em oposição ao Entendimento ${ }^{16}$; 3. Faculdade de inferiri ${ }^{17} ; 4$. Condição permanente de todas as ações arbitrárias ${ }^{18} ; 5$. Condição de prestar conta das afirmações ${ }^{19} ; 6$. Faculdade de unir os conceitos do entendimento em idéias ${ }^{20} ; 7$. Faculdade de deduzir o particular do universal ${ }^{21}$.

Assim, Schopenhauer prepara a crítica à razão pura prática a partir da confusão e indeterminação do que seja a razão dentro da primeira Crítica. A despeito do elogio ao

\footnotetext{
${ }^{12}$ M/M. p. 15 (115).

${ }^{13}$ Idem, Ibidem.

${ }^{14}$ M/M. 543-4.

${ }^{15}$ Crítica da Razão Pura (doravante CRP), pp.52-3, B24, A12.

${ }^{16}$ Idem, p.299, B356, A299.

${ }^{17}$ Id.. p. 318, B386, A330.

${ }^{18}$ Id., p. 475, B581, A553.

${ }^{19}$ Id., p. 514, B642, A 614.

${ }^{20}$ Id., p. 534, B672-3, A643-4.

${ }^{21}$ Id., p. 535, B674, A646.
} 
estilo da escrita kantiana como "secura brilhante"22, suas definições tornam-se prolixas, confusas e frouxas devido ao esforço pela simetria. Acrescenta-se que esta obscuridade, além do mais, deve-se também a imprecisões e incertezas. Seguindo o princípio cartesiano "Quo enim melius rem aliquam cincipimus, eo magis determinati sumus ad eam único modo exprimendam", ou seja, "Quanto melhor concebemos uma coisa, tanto mais estamos resolvidos a exprimi-la de um único modo", Schopenhauer conclui que a postulação de uma razão pura prática decorre diretamente da confusão e falta de determinação do que seja a razão:

Ora, se Kant tivesse investigado seriamente em que extensão se dão a conhecer essas duas faculdades diferentes de conhecimento, uma das quais é a distintiva da humanidade, e o que, conforme o uso lingüístico de todos os povos e filósofos ${ }^{23}$, se chama razão e entendimento, não teria dividido a razão em prática e teórica, sem outra autoridade senão o intellectus theoreticus e practicus dos escolásticos (que usam os termos em sentido totalmente diferente) e jamais teria feito da razão prática a fonte das ações virtuosas ${ }^{24}$.

Para Schopenhauer, Kant deveria ter determinado qual é a real definição de razão, e a partir do gênero, definir as espécies, isto é, uma vez determinado qual é a característica essencial da faculdade racional, demonstrar que os dois usos da razão - o teórico e o prático - partilham esta característica essencial. Mas isto não foi feito por Kant em nenhum momento ${ }^{25}$.

Contudo, não obstante a multiplicidade de definições para razão, e a falta de determinação de qual é a essencial, é da primeira definição citada acima que Kant deriva, segundo Schopenhauer, a razão pura prática, qual seja, faculdade dos princípios a priori. Isto porque o conhecimento do valor das ações éticas - para dar conta da exigência de universalidade -, não pode ter origem empírica, e então só pode provir da razão, já que é

\footnotetext{
${ }^{22}$ CK. p. 539.

${ }^{23}$ Adiante esta crítica de falta de conformidade dos termos kantianos com o uso feito por outros autores, definições lingüísticas e mesmo o cotidiano voltará a aparecer, sobretudo, na definição do conceito de respeito.

${ }^{24}$ CK. p. 545. Grifos do original. Cf. CK., p. 639, a origem da concepção de uma razão prática, que na citação acima Schopenhauer identifica com o intellectus practicus dos escolásticos, remonta a Aristóteles. Contudo, o estagirita entendia por razão prática apenas a razão direcionada à técnica, e não como fonte das virtudes, sendo justamente essa a contribuição da escolástica..

${ }^{25}$ Idem, p. 648.
} 
esta que determina a priori os princípios ${ }^{26}$. A razão mostra-se prática, pois, quando efetua o mesmo processo do conhecimento teórico - determinação dos objetos da experiência -, mas agora voltado às determinações das ações. Assim como a razão determina os objetos da experiência no seu uso teórico, também determina os objetos no uso prático, isto é, as leis para as ações.

Desta forma, baseado apenas no fato das duas estâncias - a teórica e a prática prescindirem da experiência, e a razão em seu uso teórico ser definida como faculdade dos princípios a priori, Kant concebeu um uso puro prático para a razão, mas, e isto é o mais crucial nesta crítica, não levou em conta as diferenças fundamentais e essenciais entre o conhecimento teórico e o prático ${ }^{27}$, que lidam com características heterogêneas. Segundo Schopenhauer, os dois processos, o da determinação de princípios a priori para o conhecimento dos objetos da natureza e o da determinação de princípios para o agir, na verdade, não podem provir de uma mesma faculdade: Kant teria reunido conhecimento teórico e ético sob a mesma rubrica de universalidade e necessidade, mas não levou em consideração que a necessidade das formas das duas instâncias é de natureza diversa. Senão, vejamos.

As formas e os conceitos a priori presentes no sujeito do conhecimento são condições de possibilidade dos objetos na experiência. A incondicionalidade das formas da razão teórica refere-se então aos objetos tal como eles têm de (muss) aparecer a nós. Ou seja, a necessidade dos a priori da razão teórica mostram-se efetivamente na experiência e apenas a ela se refere. As formas a priori contidas na sensibilidade e no entendimento do sujeito transcendental instauram a necessidade do muss, e é por meio dela que opera a razão teórica e são possíveis a matemática e a física.

A lei moral da razão prática, por sua vez, instaura uma incondicionalidade totalmente diferente ${ }^{28}$. O dever é a lei não do acontece efetivamente, como no muss da

\footnotetext{
${ }^{26}$ Com mais precisão, deveríamos dizer "princípios puros a priori", mas como Kant está preocupado ab ovo com a possibilidade dos juízos totalmente independentes da experiência, então a expressão é reduzida, e o "puro" permanece presente elipticamente.

${ }^{27}$ É do próprio texto kantiano a expressão "conhecimento prático".

${ }^{28}$ Hume já havia argumentado neste sentindo: “...em todo sistema de moral que até hoje encontrei, sempre notei que o autor segue durante algum tempo o modo comum de raciocinar (...) quando de repente, surpreendo-me ao ver que, em vez de cópulas proposicionais usuais, como é e não é, não encontro uma só proposição que não esteja conectada a outra por um deve ou não deve. Essa mudança é imperceptível, porém da maior importância. (...) seria preciso que se desse uma razão para algo que parece inteiramente inconcebível, ou seja, como essa nova relação pode ser deduzida de outras inteiramente diferentes" (HUME, D. Tratado da natureza humana. Tradução Déborah Danowski. São Paulo: UNESP, 2001).
} 
razão teórica, mas antes do que deve (soll) acontecer. Se as formas da razão teórica dizem o que tem de (muss) acontecer, a forma da razão prática diz o que deve (soll) acontecer - mas que talvez nunca aconteça efetivamente ${ }^{29}$. Assim, já que a necessidade da razão teórica e a da razão prática são tão diferentes, não podem derivar de uma mesma faculdade, e a razão deve ser o nome determinado para uma destas duas faculdades, da que instaura o muss ou da que instaura o soll ${ }^{30}$.

\subsection{O sofisma da tentativa de dedução}

Kant deduziu a existência de um uso prático da razão pura já na primeira Crítica, e com ela já o que a distingue, a criação de leis entendidas como dever absoluto (Sollen). Schopenhauer analisa esta dedução, julgando-a inadmissível, valendo-se de um sofisma. Vejamos primeiro a argumentação kantiana:

Com efeito, não é apenas aquilo que estimula, isto é, que afecta imediatamente os sentidos que determina a vontade humana; também possuímos um poder de ultrapassar as impressões exercidas sobre a nossa faculdade sensível de desejar, mediante representações do que é, mesmo longinquamente, útil ou nocivo; mas estas reflexões em torno do que é desejável em relação a todo o nosso estado, quer dizer, acerca do que é bom e útil, repousam sobre a razão. Por isso (daher), esta também dá leis, que são imperativos, isto é, leis objectivas da liberdade e que exprimem $o$ que deve (soll) acontecer, embora não aconteça, e distinguem-se assim das leis naturais, que apenas tratam do que acontece; pelo que são também chamadas leis práticas ${ }^{31}$.

\footnotetext{
${ }^{29} \mathrm{Cf}$, definição na primeira Critica, p. 638, B830, A802: "Por isso, esta [a razão] também dá leis, que são imperativos, isto é, leis objetivas da liberdade e que exprimem o que deve acontecer, embora nunca aconteça...", grifos do original. Também no prefácio da Fundamentação da metafísica dos costumes, p. 103: A moral pura determina leis "segundo as quais tudo deve acontecer, mas ponderando também as condições sob as quais muitas vezes não acontece o que devia acontecer". Grifo nosso. "...nach denen alles geschehen soll, aber doch auch mit Erwägung der Bedingungen, unter denen es öfters nicht geschieht." GMS, p.11.

${ }^{30}$ Cf. o filósofo diz em Handschriftliche Nachlass II, pp. 302-4, apud SQD, pp. 150-1.

${ }^{31}$ CRP., p. 638, B830, A802. Grifos do original. A tradução usada por nós deste trecho citado por Schopenhauer, contém diferenças: "Não apenas o que estimula, isto é, o que afeta imediatamente os sentidos, determina o arbítrio humano mas também possuímos uma faculdade de ultrapassar as impressões da nossa faculdade sensível de desejar, através de representações daquilo que, até mesmo da maneira mais remota, é útil ou nocivo. Semelhantes ponderações acerca daquilo que é digno de desejo em relação a nossa condição, isto é, em relação ao que é bom e útil, repousam sobre a razão. A razão, portanto, dá leis, que são imperativos, isto é, leis objetivas da liberdade e dizem o que deve acontecer, embora talvez nunca aconteça". CK., p. 650.
} 
O argumento tem duas partes. Primeiro, há uma definição da atividade racional, que dá ao homem a capacidade de não obedecer apenas e imediatamente às afecções: "Com efeito, não é apenas aquilo que estimula, isto é, que afecta imediatamente os sentidos que determina a vontade humana; também possuímos um poder de ultrapassar as impressões exercidas sobre a nossa faculdade sensível de desejar, mediante representações do que é, mesmo longinquamente, útil ou nocivo" ${ }^{32}$. Esta atividade da razão consiste, então, na reflexão acerca de todas as condições as quais o homem está sujeito, ou seja, não apenas em relação à representação presente, mas também em relação à representação de condições futuras: "mediante representações do que é, mesmo longinquamente, bom e útil" atividade racional, na direção dos nossos atos, torna-nos livres em relação aos motivos presentes e imediatos, isto através da representação de motivos futuros, e possibilita, pois, que ajamos visando outros motivos que não só os presentes, determinados apenas pela sensibilidade.

Esta primeira parte é subscrita por Schopenhauer, que no $\S 16$ de $O$ mundo como vontade e como representação também apresenta este processo racional como razão prática:

Já no início de nossa consideração acerca dessa faculdade [a razão] observamos, em termos gerais, como a ação e o comportamento do homem se diferenciam bastante da ação e do comportamento animal, e como semelhante diferença deve ser vista tão-somente como conseqüência da presença de conceitos abstrato na consciência. A influência destes sobre a nossa existência inteira é tão determinante e significativa que, em certo sentido, pode-se dizer que estamos para os animais, assim como os animais que vêem estão para os destituídos de olhos (certas larvas, vermes, zoófitos). (...) O homem, ao contrário, em virtude do conhecimento in abstrato, abrange, ao lado do presente efetivo e próximo, ainda o passado inteiro e o futuro, junto com o vasto reino das possibilidades. (...) Aqui de fato é possível dizer que a razão se exterioriza de maneira PRÁTICA. Portanto, em qualquer lugar onde a conduta é conduzida pela faculdade racional, os motivos são conceitos abstratos, e o determinante não são as representações intuitivas, particulares, nem a impressão do momento que conduz o animal: ai se mostra a RAZÃO PRÁTICA. Que, todavia, tudo isso seja por inteiro diferente e independente do valor moral da ação, que a ação racional e virtuosas são suas coisas completamente distintas... ${ }^{34}$

\footnotetext{
${ }^{32}$ Ibidem.

${ }^{33}$ Ibidem. Grifo meu.

${ }^{34}$ M. pp. 139-41.Grifos do original.
} 
A segunda parte do argumento kantiano, contudo, apresenta, aos olhos de Schopenhauer, um salto. Daquela descrição de um processo racional que possibilita que o homem não aja apenas pela influência das afecções ou motivos presentes, Kant apresenta a razão como faculdade que produz leis necessárias e categóricas: "Por isso, esta também dá leis, que são imperativos, isto é, leis objectivas da liberdade e que exprimem o que deve acontecer, embora não aconteça, e distinguem-se assim das leis naturais, que apenas tratam do que acontece; pelo que são também chamadas leis práticas" ${ }^{35}$.

Desta forma, o sofisma é o seguinte, segundo Schopenhauer: as duas partes do argumento são estranhas entre si, pois tratam de operações diversas, sem ligação; a suposta ligação é forjada apenas pela conjunção "por isso"/"portanto" (daher), que tenta estabelecer uma relação de fundamento e conseqüência. O fundamento, a razão como faculdade de representações abstratas, estabelece como conseqüência que os homens não agem apenas por estímulos sensíveis, mas também por representações abstratas, que não passam aqui de considerações sobre possibilidades futuras.

Assim, um homem seco de sede pode abster-se de beber a água de um poço repleto de moscas, considerando que esta pode estar infectada e trazer-lhe doenças. Não obstante a enorme sede, o homem age movido pelo motivo abstrato que lhe apresenta a possibilidade de se infeccionar, e não pelo motivo presente da sensibilidade. Nesta capacidade humana da qual a razão é responsável não há nenhuma consideração moral, muito menos estabelece um deve incondicionado, mas somente, em linguagem kantiana: um conselho de prudência $^{36}$.

A primeira parte do argumento traz em si fundamento e conseqüência, sem a necessidade de um complemento. E a segunda parte, desconexa, é ligada pelo "intermédio do fórceps de um PORTANTO, que, de modo ousado e atrevido, poder-se-ia até dizer desavergonhadamente se intromete entre duas proposições inteiramente estranhas"37, que, não obstante o artifício sofístico da conjunção, não está fundamentada na primeira parte do argumento.

\footnotetext{
${ }^{35}$ CRP., p. 638, B830, A802.

${ }^{36}$ Cf. definição encontrada na Fundamentação da metafísica dos costumes, p. 126: “O conselho contém, na verdade, uma necessidade, mas que só pode valer sob a condição subjetiva e contingente de este ou aquele homem considerar isto ou aquilo como contando para a sua felicidade."

${ }^{37}$ CK., p. 649.
} 
Desta forma, Schopenhauer acusa uma falta de fundamento na dedução da razão pura prática e da sua capacidade de produzir a incondicionalidade do soll. Isto porque, como vimos, a atividade distintiva da razão, definida e exposta na primeira parte do argumento, fundamenta apenas a liberdade do homem em relação às afecções. Para que a segunda parte do argumento pudesse ter um fundamento verdadeiro, seria necessário deduzi-la de uma faculdade que em sua atividade essencial instaurasse a incondicionalidade do soll, ou seja, uma faculdade diferente da razão teórica, que instaura apenas a incondicionalidade do muss. Esta faculdade que supostamente engendra leis com a incondicionalidade do soll, diz Schopenhauer, não foi nunca demonstrada, provada ou legitimamente deduzida, mas apenas sofisticamente deduzida da razão teórica, com sua incondicionalidade diversa.

\subsection{Genealogia da razão pura prática}

O filósofo da Vontade se pergunta ainda sobre a origem da concepção de uma razão pura prática: "Se quisermos chegar ao fundamento da admissão da razão prática, teremos de explorar ainda mais sua árvore genealógica (Stammbaum)" ${ }^{38}$. A raiz desta árvore, uma vez trazida à luz, implica uma interdição avassaladora, e o resultado desta investigação é mais penetrante e polêmica justamente por acusar incoerência entre o que Kant afastou como dogma transcendente na primeira Crítica e o que lhe serviu de fundamento para a moral na segunda. A raiz, argumenta Schopenhauer, não é outra senão a psicologia racional.

A psicologia racional define o homem como composto de duas substâncias heterogêneas: o corpo material e a alma imaterial. Esta é imortal; aquela, mortal. O conhecimento e o querer são puros quando guiados pela alma imaterial, sendo que a vontade é pura e certa quando resultado desta atividade pura da alma (intelecto puro), que opera apenas por conceitos abstratos, universais e inatos; mas uma vez que a alma esteja em ligação e sobre influência do corpo, sua eficácia fica reduzida e mesmo confusa, e a vontade, já que só existe em conseqüência do conhecer, que neste caso está mesclado com os dados sensoriais, só pode ser inferior, e má mesmo, por obedecer aos apetites corporais,

\footnotetext{
${ }^{38}$ M/M, p. 63 (151).
} 
isto é, a representações intuitivas, e não mais apenas a representações abstratas ${ }^{39}$. Desta forma, temos um intelecto puro, isto é, conhecimento puramente abstrato, formal, universalizante, que determina a vontade, que neste caso é boa; e temos um intelecto inferior, pois ligado ao corpo, e responsável pelo conhecimento intuitivo, limitado, particular, e que, portanto, só pode determinar a vontade de maneira também inferior, por móbeis empíricos.

Segundo Schopenhauer, esta teoria dogmática, na verdade um pressuposto teológico ${ }^{40}$, é a raiz da concepção de uma razão pura prática e a autonomia de sua determinação, isto é, estas não seriam possíveis sem este dogma, e Kant dele se serviu sem perceber que era o mesmo que antes criticara:

De uma reminiscência não claramente consciente (Aus der undeutlich bewußten Remineszenz) de tal concepção proveio, finalmente, a doutrina kantiana da autonomia da vontade, que, tomada como voz da razão pura prática, é legisladora para todo ser enquanto racional e conhece meramente razões formais de determinação, em oposição às materiais, que, como tal, determinam apenas a faculdade de desejar inferior (das niedere Begehrungsvermögen) que age contra a superior (obere $)^{41}$.

\section{Conclusão}

São conhecidas as tentativas, notadamente em Schiller e Fichte, de reparar a tese kantiana do primado da razão prática, prejudicada por seu formalismo, a partir de uma manobra de conciliação entre o rigorismo da lei moral e a sensibilidade material dos indivíduos. É neste sentido que a sensibilidade irá gradativamente desvencilhar-se do modelo restritivamente mecânico das inclinações causais, ganhando espaço uma investigação orgânica das pulsões ou sentimentos morais. O ponto de maior dificuldade, nesta esteira, parece ser a adaptação transcendental dos impulsos, ou ainda, em outras palavras, da motivação moralmente subjetiva à fundamentação objetiva das ações eticamente consideradas. Schopenhauer, por outro caminho, esforça-se por depurar da

\footnotetext{
39 Schopenhauer, para apontar a distinção entre representações abstratas e intuitivas, cita a definição cartesiana, M/M, p.64 (153): "Intellectio pura est intellectio, cuae circa nullas imagines corpóreas versatur", "O intelecto puro é o intelecto que não se refere a nenhuma imagem corpórea"..

${ }^{40}$ Cf.: Schopenhauer e a questão do Dogmatismo, p. 152.

${ }^{41} \mathrm{M} / \mathrm{M}$, p. 66 (153-4). Grifos do original.
} 
filosofia moral o cariz prescritivista (em seu entender, arcaico), preservando dos seus antecessores o que neles havia de mais original em termos de filosofia transcendental, aquela introdução do sentimento, menos como dado irredutivelmente subjetivo do que motivação concreta das ações, portanto, como verdadeiro impulso. Se em sua metafísica, o fundamento mais radical não só do homem, mas de todo e qualquer ser efetivo, é esse impulso - aquele mero ímpeto cego que caracteriza a Vontade - de vocação primordialmente moral, aqui, na polêmica com seus pares, a sua contraparte é a acusação virulenta de dogmatismo racionalista, inextirpável à esperança de uma razão sublimemente autônoma, que à cata de um distintivo para a dignidade humana, corre o risco de hipersensibilizá-la para a luz do dia:

De resto, no que me concerne, tenho de confessar: em minha limitação, não consigo apreender ou representar de qualquer modo senão como sexto sentido dos morcegos aquela faculdade de razão que percebe diretamente, ou apreende, ou intui intelectualmente o supra-sensível, o absoluto, junto com as longas narrativas que acompanham tudo isso ${ }^{42}$.

\section{Referências}

SCHOPENHAUER, Arthur. Über die Grundlage der Moral. Sämtliche Werte, von Julius Frauenstädt besorgten Gesamtausg, neu bearb. u. hrsg. von Arthur Hübscher. Mannheim: Brockhaus, 1988.

. O mundo como vontade e como representação, $1^{\circ}$ tomo. Tradução, apresentação, notas e índices de Jair Barboza. São Paulo: Editora UNESP, 2005.

. Sobre o fundamento da moral. Tradução: Maria Lúcia Mello Oliveira Cacciola. $2^{\mathrm{a}}$ ed. São Paulo: Martins Fontes, 2001. (Coleção clássicos)

KANT, Immanuel. Grundlegung zur Metaphysik der Sitten. Werkausgabe: in 12 Bänden - Bald 7. Hrsg. von Wilhelm Weischedel. Frankfurt am Main: Suhrkamp - Taschenbuch Wissenschft, 1991.

- Crítica da Razão Pura. Tradução: Manuela Pinto dos Santos e

Alexandre Fradique Morujão. Lisboa: Edição da Fundação Calouste Gulbekian: 2001.

FICHTE, Johann Gottlieb. Sobre o conceito da Doutrina-da-ciência ou Da assim chamada filosofia (1794). Tradução: Rubens Rodrigues Torres Filho. In: Os pensadores, $3^{a}$ ed. São Paulo: Nova Cultural, 1988.

${ }^{42}$ CK, p. 647. 
BARBOZA, Jair. Os limites da expressão, linguagem e realidade em Schopenhauer. In: Veritas, Volume 50, $\mathrm{n}^{\circ}$ 1, pp. 127-135. Porto Alegre: 2005.

BONACCINI, Juan Adolfo. Kant e o problema da coisa em si no idealismo alemão. Rio de Janeiro: Relume dumará, 2003.

BARRENECHEA, José María Artola. El discurso de Schopenhauer sobre la «cosa en si». In: Anales del Seminario de Metafisica, $\mathrm{n}^{\circ}$ 23-1989/83-118, 1987-88-89. Ed. Universidad Complutense, Madrid. Também disponível em: $<$ http://www.ucm.es/BUCM/revistas/fs1/15756866/articulos/ASEM8989110083A.PDF>. Acesso em 4 de agosto de 2007.

CACCIOLA, Maria Lúcia Mello e Oliveira. Schopenhauer e a questão do dogmatismo. São Paulo: EDUSP - Editora da Universidade de São Paulo, 1994.

CARTWRIGHT, David E. Schopenhauer's Narrower Sense of Morality. In: The Cambridge companion to Schopenhauer, pp. 252-92. Edit by Christopher Janaway. Cambridge: Cambridge University Press, 1999.

ZINGANO, Marco Antonio. Razão e história em Kant. São Paulo: Editora Brasiliense, 1988.

Recebido: 07/07/11

Received: 07/07/11

Aprovado: $10 / 08 / 11$

Approved: 08/10/11 